\title{
Introgression of Resistance to Powdery Mildew Conferred by Chromosome 2R by Crossing Wheat Nullisomic 2D with Rye
}

\author{
Diao-Guo An ${ }^{1,3,4^{*}}$, Li-Hui Li ${ }^{2}$, Jun-Ming Li ${ }^{1}$, Hong-Jie $\mathrm{Li}^{2}$ and Yong-Guan $\mathrm{Zhu}^{3}$ \\ (1. Centre of Agricultural Resources, Institute of Genetics and Developmental Biology, the Chinese Academy of Sciences, \\ Shijiazhuang 050021, China; \\ 2. Institute of Crop Sciences, the Chinese Academy of Agricultural Sciences, Beijing 100081, China; \\ 3. Research Center for Eco-environmental Sciences, the Chinese Academy of Sciences, Beijing 100085, China; \\ 4. Graduate School of the Chinese Academy of Sciences, Beijing 100039, China)
}

\begin{abstract}
Using the nullisomic back-cross procedure, four wheat-rye chromosome substitution 2R (2D) lines with different agronomic performance, designated WR02-145-1, WR01-145-2, WR02-145-3, and WR02-145-4, were produced from a cross between 2D nullisomic wheat (Triticum aestivum L. cv. "Xiaoyan 6") and rye (Secale cereale L. cv. "German White"). The chromosomal constitution of 2n=42=21 in WR02-145 lines was confirmed by cytological and molecular cytogenetic methods. Using genomic in situ hybridization on root tip chromosome preparations, a pair of intact rye chromosomes was detected in the WR02-145 lines. PCR using chromosome-specific primers confirmed the presence of $2 R$ chromosomes of rye in these wheat-rye lines, indicating that WR02-145 lines are disomic chromosome substitution lines 2R (2D). The WR02-145 lines are resistant to the powdery mildew (Erysiphe graminis DC. f. sp. tritici E. Marchal) isolates prevalent in northern China and may possess gene(s) for resistance to powdery mildew, which differ from the previously identified Pm7 gene located on chromosome 2RL. The newly developed "Xiaoyan 6"- "German White" 2R (2D) chromosome substitution lines are genetically stable, show desirable agronomic traits, and are expected to be useful in wheat improvement.
\end{abstract}

Key words: genomic in situ hybridization; nullisomic back-cross procedure; PCR; powdery mildew resistance; wheat-rye chromosome substitution line.

An DG, Li LH, Li JM, Li HJ, Zhu YG (2006). Introgression of resistance to powdery mildew conferred by chromosome 2 R by crossing wheat nullisomic 2D with rye. J Integrat Plant Biol 48(7), 838-847.

www.blackwell-synergy.com; www.jipb.net

The introgression of rye (Secale cereale L.; $2 n=2 x=14 ; R$ genome) chromatin has proved to be useful in wheat (Triticum aestivum L. em Thell) improvement (Zeller and Hsam 1983; Rabinovich 1998). Rye has been used extensively as a valuable

Received 13 Oct. 2005 Accepted 23 Dec. 2005

Supported by the National Natural Science Foundation of China (30471079), National Key Technologies R \& D Program in the $10^{\text {th }}$ Five-Year Plan (2004BA525B03), and the Knowledge Innovation Project of the Chinese Academy of Sciences (KSCX2-SW-304).

*Author for correspondence. Tel: +86 (0)311 8587 1746; Fax: +86 (0)311 8581 5093; E-mail: <andiaoguo@163.com>. source of genes for resistance to various diseases and pests, such as powdery mildew (caused by Erysiphe graminis DC. f. sp. tritici E. Marchal; Heun and Friebe 1990; Friebe et al. 1994), stripe rust (Puccinia striiformis Westend. f. sp. tritici Eriks.; Miller 1984), leaf rust ( $P$. triticina Eriks.; Mclntosh et al. 1995), stem rust $(P$. graminis Pers. f. sp. tritici Eriks. et Henn.; Stewart et al. 1968), Barley yellow dwarf virus (BYDV; Nkongolo et al. 1992), hessian fly (Mayetiola destructor Say; Friebe et al. 1990), greenbug (Schizaphis graminum Rondani; Sebesta et al. 1994), and cereal cyst nematode (Heterodera avenae Wollenweber; Asiedu et al. 1990). Since the first wheat-rye hybrid was obtained in 1875 (Wilson 1875), many wheat-rye chromosome addition, substitution, and translocation lines have been 
developed. The agronomic success of wheats with the T1BL-1RS wheat-rye chromosome translocation has prompted further attempts to transfer rye chromatin into wheat genome.

The introgression of genes from rye into wheat via chromosome substitution is a proven approach. Wheat-rye chromosome substitution lines are a source of genes for desirable traits in wheat improvement, which can be developed using monosomic (Sears 1968) and monotelosomic methods (Kota and Dvoák 1985). Chromosome substitution also occurs in progenies derived from anther and embryo in vitro cultures (Hu et al. 1988; Li et al. 1998). In order to quickly develop an alien chromosome substitution line, Li et al. (1982) developed a nullisomic back-crossing procedure in which nullisomic wheats were crossed with wild relatives of wheat. Using this method, chromosome $4 \mathrm{R}$ of rye was introduced into wheat as a replacement for chromosome 4D of wheat (Zhang et al. 1990). Xu et al. (1992) produced wheat-Aegilops speltoides Tausch $(2 n=2 x=14) 4 S(4 D)$ chromosome substitution lines.

Winter wheat cultivar "Xiaoyan 6" is derived from a wheatThinopyrum ponticum (Host) Liu et Wang $(2 n=10 x=70$; StStEeEbEx genomes) cross and possesses characteristics of promising quality and high yield, earliness, stress tolerance, and wide adaptation (Li et al. 1990; Wei et al. 2000). This cultivar has been grown for two decades, but has recently become vulnerable to certain diseases, such as powdery mildew. Rye is a valuable source of genes for resistance to powdery mildew, such as $P m 7$ located on chromosome arm 2RL, Pm8 and Pm17 on chromosome arm 1RS, and Pm20 on chromosome arm 6RL (McIntosh et al. 2003). Since resistance to powdery mildew conferred by $P m 7, P m 8$, and $P m 17$ has been overcome in northern China (Zhuang and Li 1993; Zhuang 2003), there is a need to transfer other resistance genes from rye to improve the resistance of "Xiaoyan 6" to powdery mildew, because this cultivar is still grown in various wheat-producing regions in China.

Several methods can be used to detect rye chromatin transferred into wheat (Le et al. 1989; Schwarzacher et al. 1989; Mukai et al. 1992; Rogowsky et al. 1993; Brunell et al. 1999). Of these, in situ hybridization using probes either from genomic DNA (GISH) or cloned DNA sequences (fluorescence in situ hybridization (FISH); Mukai and Nakahara 1993) allows the detection of rye chromosomes or chromosome segments. PCR using DNA primers specific for the rye genome also is a valuable method for the identification of rye chromatin in wheat genetic backgrounds (Lee et al. 1993). In this way, rye chromosomes or chromosome segments can be discriminated in terms of chromosome substitution, addition, and translocation.

The present study dealt with the development of chromosome substitution lines involving rye chromosome $2 \mathrm{R}$ by the nullisomic back-crossing procedure. The wheat-rye hybrids produced were characterized by cytological and molecular cytogenetic methods and resistance to powdery mildew was evaluated by inoculation with isolates that are prevalent in northern China.

\section{Results}

\section{Production of WR02-145 wheat-rye lines}

Nullisomic 2D wheat $(2 n=40)$ of "Xiaoyan 6" behaved 20 bivalents during meiosis and was crossed with "German White" rye. Of the $61 \mathrm{~F}_{0}$ immature embryos, 28 plants were obtained by embryo rescue on $\mathrm{MS}$ medium. These regenerated $\mathrm{F}_{1}$ plants were stored at $4{ }^{\circ} \mathrm{C}$ until field transplantation. Among them, $12 \mathrm{~F}_{1}$ plants had a chromosome number $2 n=27$ (Figure 1A). Because rye chromosomes rarely partnered with wheat homoeologous chromosomes of $F_{1}$ plants behaved 27 univalents (Figure 1B). After chromosome doubling, eight $F_{1}$ hybrid plants with $2 n=54$ were obtained (Figure 1C). The spikes of these plants resembled the rye parent, showing longer spikes and more florets than wheat, whereas plant heights were similar to those of wheat. Plants were back-crossed with nullisomic 2D, resulting in 32 $\mathrm{BC}_{1} \mathrm{~F}_{1}$ seeds. Although the progenies were morphologically intermediate between rye and wheat, plants that resembled the wheat parent grew well in the field. Segregation was observed in plant height and reactions to powdery mildew isolates. Six powdery mildew resistant plants $(2 n=47)$ were back-crossed as the maternal parent with nullisomic $2 \mathrm{D}$, resulting in $26 \mathrm{BC}_{2} \mathrm{~F}_{1}$ seeds. Twenty-two $\mathrm{BC}_{2} \mathrm{~F}_{1}$ seedlings were tested for their reaction to powdery mildew and resistant plants were examined cytologically. Four progenies with chromosome number $2 n=41$ were self-pollinated. Of the $\mathrm{BC}_{2} \mathrm{~F}_{2}$, four plants having chromosome number $2 n=42$ were candidate wheat-rye $2 R(2 D)$ substitution lines and were designated WR02-145-1, WR02-145-2, WR02-145-3, and WR02-145-4, which were self-pollinated for an additional three generations before molecular cytogenetic characterization.

\section{Evaluation of agronomic performance and reaction to powdery mildew of the WR02-145 wheat-rye lines}

Following three consecutive generations of selfing, no segregation was observed in the four WR02-145 wheat-rye lines, either in morphology or cytology. The plants resembled common wheat, except for a thin gray-green leaf color. Compared with nullisomic 2D wheat and rye, the WR02-145 lines grew vigorously, with an average fertility for the four WR02-145 lines of $93.2 \%$ based on 30 plants measured for each line. The seeds were plump and the average 1000 -kernel weight ranged from 38 to $40 \mathrm{~g}$ (Table 1; Figure 2A).

In a greenhouse test, 20 individual plants of the four WR02145 lines each were tested for reaction to powdery mildew. "German White" rye and WR02-145 lines were resistant to the 


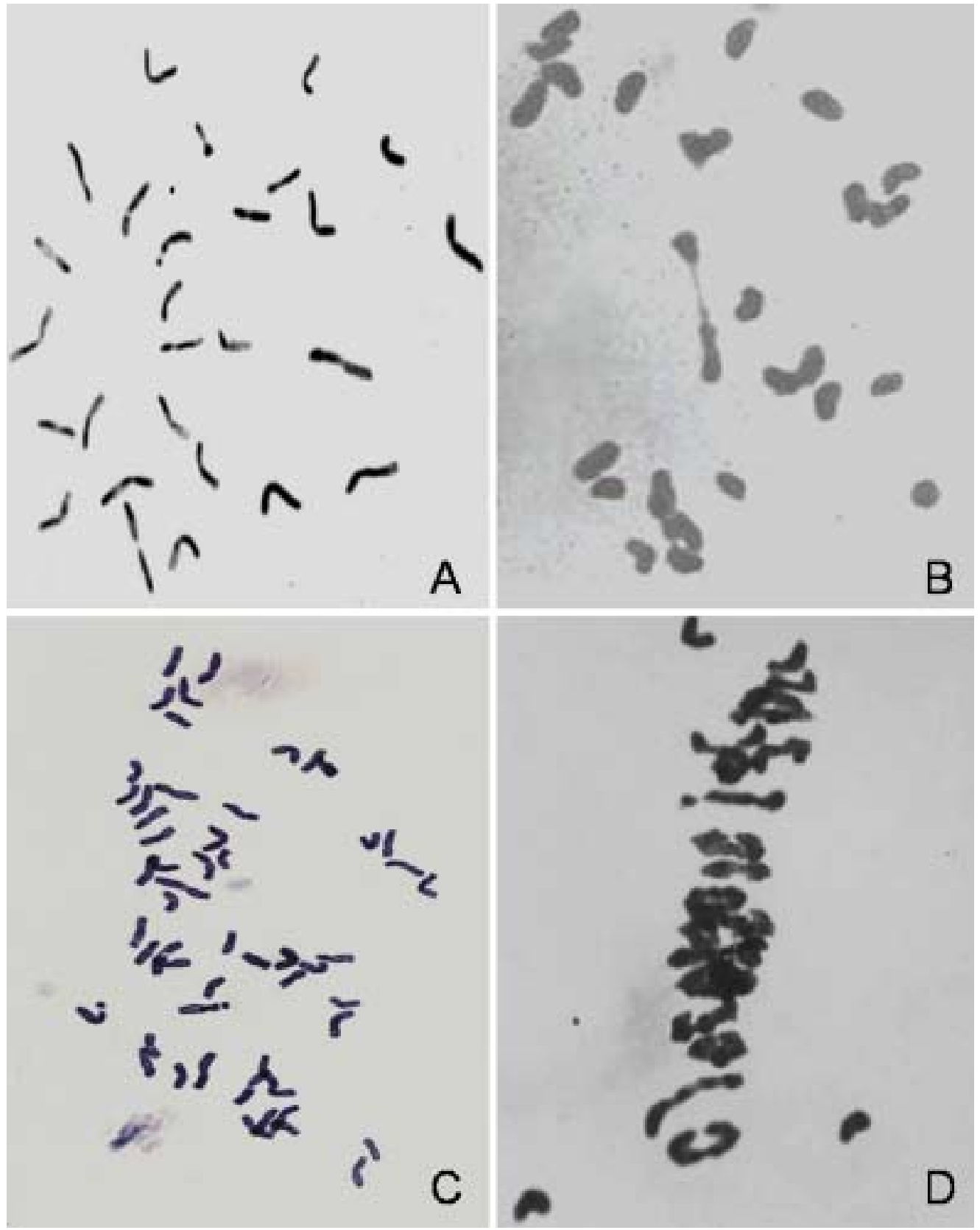

Figure 1. Cytological analyses.

(A) Chromosome numbers of $F_{1}$ hybrids derived from a cross between nullisomic 2D of "Xiaoyan 6" wheat and "German White" rye, $2 n=27$. (B) Chromosome pairing configuration of the $F_{1}$ hybrid derived from a cross between nullisomic 2D of "Xiaoyan 6" wheat and "German White" rye, $2 n=20 ' W+7 ' R$.

(C) Chromosome number of an $F_{1}$ plant following treatment with cholchicine, $2 n=54$.

(D) Chromosome paring patterns at meiotic metaphase I. WR02-145 lines × "Chinese Spring", showing 20 bivalents and two univalents, one from "Chinese Spring" wheat and the other from rye. 
Table 1. Agronomic traits of the WR02-145 wheat-rye chromosome substitution lines

\begin{tabular}{|c|c|c|c|c|c|c|c|}
\hline Lines or parents & $\begin{array}{c}\text { Plant height } \\
(\mathrm{cm})\end{array}$ & $\begin{array}{c}\text { No. of spikes } \\
\text { per plant }\end{array}$ & $\begin{array}{l}\text { Spike length } \\
(\mathrm{cm})\end{array}$ & $\begin{array}{c}\text { No. kernels } \\
\text { per spike }\end{array}$ & $\begin{array}{c}\text { No. spikelets } \\
\text { per spike }\end{array}$ & $\begin{array}{c}1 \text { 000-kernel } \\
\text { weight }(\mathrm{g})\end{array}$ & $\begin{array}{c}\% \text { Seed } \\
\text { setting }\end{array}$ \\
\hline WR02-145-1 & 92 & 17 & 10.5 & 65 & 23 & 38.9 & 94.0 \\
\hline WR02-145-2 & 88 & 20 & 11.5 & 67 & 24 & 40.2 & 93.0 \\
\hline WR02-145-3 & 90 & 18 & 10.5 & 60 & 21 & 38.5 & 95.2 \\
\hline WR02-145-4 & 87 & 21 & 11.0 & 68 & 25 & 40.6 & 90.4 \\
\hline Nullisomics 2D & 59 & 12 & 7.0 & 37 & 15 & & 60.5 \\
\hline "German White" rye & 133.5 & 26 & 13.2 & 83 & 42 & & 96.6 \\
\hline
\end{tabular}

mixture of powdery mildew isolates collected from northern China, with an infection type (IT) score of 0 for "German White" and scores of 1 or 2 for the WR02-145 lines. All plants of "Xiaoyan 6", nullisomic 2D, and susceptible check "Mingxian 169" were susceptible (IT scores of 4).

In field experiments, plants of the WR02-145 lines and "German White"' developed no symptoms of powdery mildew or necrotic flecks (IT 0 or 0 ;) with a disease severity score of 1 and these were regarded as highly resistant. In contrast, the leaves of "Xiaoyan 6" and nullisomic 2D were covered by powdery mildew spores (IT 4) and the disease severity score was 9; these plants were considered susceptible (Figure 2B).

\section{PCR analysis of WR02-145 wheat-rye lines}

Using the chromosome 2R-specific primers R1 and R2, the 473 bp PCR diagnostic fragment was produced in the four WR02145 lines and "Chinese Spring" wheat-"Imperial" rye 2R(2D) chromosome substitution line, which indicated the presence chromatin 2R in WR02-145. This 473-bp band was also amplified in the rye parent, but was not amplified in "Xiaoyan 6" or nullisomic 2D, "Chinese Spring”, "Mingxian 169", Lovrin 10, and Lovrin 13 (T1BL-1RS translocation lines), indicating that they did not contain 2RS chromatin of rye (Figure 3 ).

\section{Cytological and GISH analyses of WR02-145 wheat-rye lines}

To determine the mitotic and meiotic chromosome constitutions of the wheat-rye derivatives, karyotypes were examined on at least 20 metaphase chromosome spreads from eight seeds for each genotype. The WR02-145 lines had 42 chromosomes and most pollen mother cells (PMCs; average $96.5 \%$ ) had 21 bivalents at the first meiotic metaphase. When crossed with Chinese Spring wheat, most cells of the $F_{1}$ plants had 20 bivalents and two univalents (Table 2; Figure 1D), indicating that a pair of wheat chromosomes had been replaced by a pair of rye chromosomes in the WR02-145 lines.

Eight to 10 individual plants from the four WR02-145 lines were tested for the presence of rye chromosomes by GISH. Using rye genomic DNA as a probe and wheat genomic DNA as a blocker, GISH on mitotic metaphase chromosomes permitted the identification of a pair of rye chromosomes in the four WR02145 lines as replacements for the two wheat chromosomes. The rye chromosomes were easily distinguished from the wheat chromosomes by their bright-green hybridization signals along the entire length of the chromosomes, whereas the wheat chromosomes were counterstained red with propidium iodide (PI; Figure $2 \mathrm{C}$ ). Taking results from the PCR, cytological and GISH investigations together, the WR02-145 wheat-rye hybrids were determined to be $2 \mathrm{R}(2 \mathrm{D})$ wheat-rye chromosome substitution lines.

\section{Discussion}

The rye chromosome $2 \mathrm{R}$ carries genes for disease resistance,

Table 2. Chromosome paring patterns of WR02-145 lines and $F_{1}$ plants of crosses between WR02-145 lines and Triticum aestivum "Chinese Spring" (CS) at meiotic metaphase I

\begin{tabular}{|c|c|c|c|c|c|}
\hline \multirow{2}{*}{ Lines or crosses } & \multirow{2}{*}{$\begin{array}{c}\text { Total no. cells } \\
\text { observed }\end{array}$} & \multicolumn{4}{|c|}{ No. cells (\% of total cells observed) } \\
\hline & & $211 I$ & $20 I I+2 I$ & $19 I I+4 I$ & Others \\
\hline WR02-145-1 & 120 & $115(95.8)$ & $5(4.2)$ & & \\
\hline WR02-145-2 & 101 & $99(98.0)$ & $2(2.0)$ & & \\
\hline WR02-145-3 & 89 & $86(96.6)$ & $3(3.4)$ & & \\
\hline WR02-145-4 & 68 & $65(95.6)$ & $2(2.9)$ & & $1(1.5)$ \\
\hline WR02-145-1×CS & 121 & & $111(91.7)$ & $8(6.6)$ & $2(1.7)$ \\
\hline WR02-145-2×CS & 80 & & $64(80.0)$ & $11(13.7)$ & $5(6.3)$ \\
\hline WR02-145-3×CS & 110 & & $95(86.4)$ & $10(9.1)$ & $5(4.5)$ \\
\hline WR02-145-4×CS & 62 & & 52 (83.9) & $6(9.7)$ & $4(6.4)$ \\
\hline
\end{tabular}



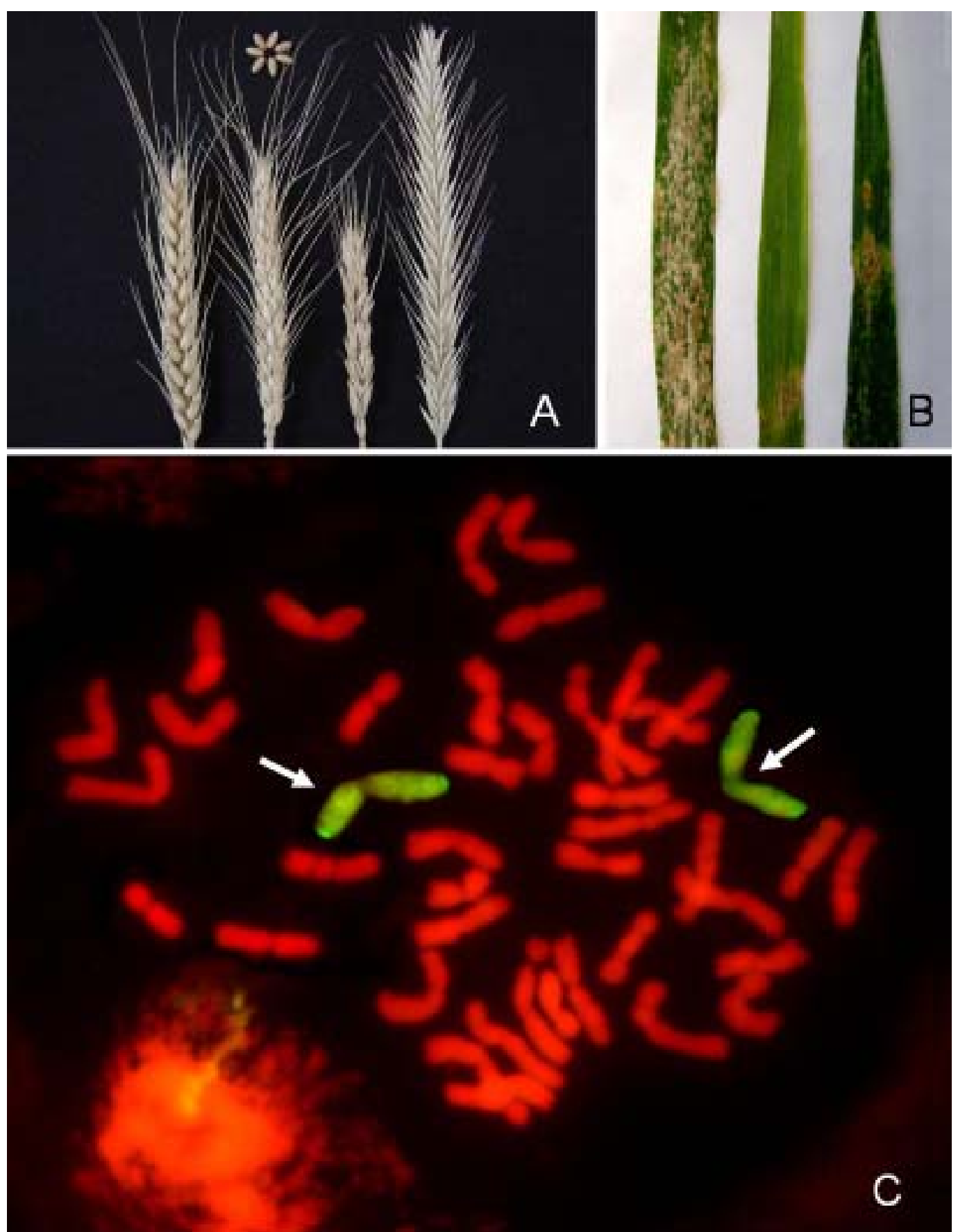

Figure 2. Agronomic traits, powdery mildew reactions and genomic in situ hybridization.

(A) Spikes of "German White" rye (right), nullisomic 2D of "Xiaoyan 6" wheat (middle 2), chromosome substitution lines WR02-145 (left and middle 1), and seeds of WR02-145 line (above).

(B) Powdery mildew reactions of nullisomic 2D (left), "German White" (middle), and WR02-145-1 line (right).

(C) GISH of mitotic metaphase chromosomes of the WR02-145 lines, using rye genomic DNA as a probe in the presence of "Chinese Spring" genomic DNA as a blocker.

A chromosome pair of rye was visualized as bright-green fluorescein isothiocyanate hybridization signals (arrows). 


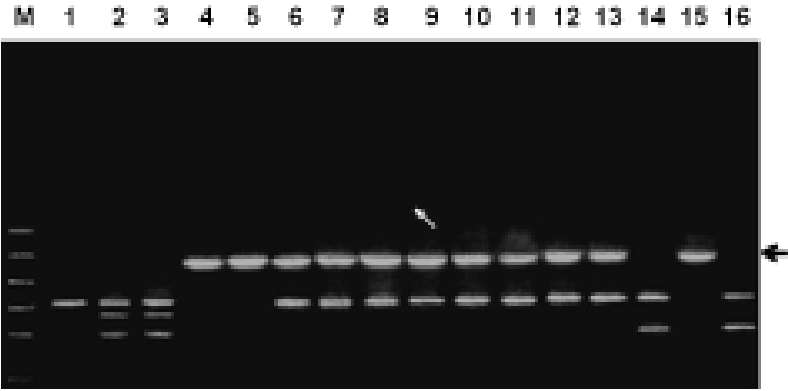

Figure 3. PCR products amplified by primers R1 and R2 specific for chromosome $2 \mathrm{R}$ of rye.

Lane 1, "Chinese Spring"; lane 2, Lovrin 10; lane 3, Lovrin 13; lanes 4, 5, 15, "German White"; lanes 6, 7, "Chinese Spring" - "Imperial" 2R(2D) chromosome substitution line; lanes 8, 9, WR02-145-1; lanes 10, 11, WR02-145-2; lane 12, WR02-145-3; lane 13, WR02-145-4; lane 14, nullisomic 2D of "Xiaoyan 6"; lane 16, "Xiaoyan 6"; M, 100bp DNA ladder (Dingguo Biotechnology, Beijing, China). The arrow indicates the 473-bp diagnostic DNA fragments.

such as powdery mildew (Heun and Friebe 1990), leaf rust (McIntosh et al. 1995), stem rust (Brunell et al. 1999), hessian fly (Friebe et al. 1990), and tolerance to BYDV and drought stress, as well as a gene for short straw (Schlegel et al. 1998; Merker and Forsström 2000), which are useful characteristics in wheat improvement. "Xiaoyan 6" was grown extensively in China for approximately 20 years, covering over $670000 \mathrm{hm}^{2}$ (Zhuang 2003). However, this cultivar has recently become vulnerable to powdery mildew. Rye chromatin was not present in "Xiaoyan 6" (Li et al. 1990). In order to improve the resistance of "Xiaoyan 6" to powdery mildew and because of the multiple potentially useful genes on rye chromosome $2 \mathrm{R}$, we transferred this chromosome to wheat "Xiaoyan 6" and produced new 2R(2D) "Xiaoyan 6" wheat-"German White" rye substitution lines.

Lind (1982) reported that chromosome $2 \mathrm{R}$ conditioned a high degree of powdery mildew resistance. Heun and Friebe (1990) found that chromosome 2R from "Prolific" rye was a source of resistance to powdery mildew and carried a more effective $\mathrm{Pm} 7$ allele and/or some further powdery mildew resistance genes. In the present study, the new $2 \mathrm{R}(2 \mathrm{D})$ wheat-rye chromosome substitution lines also conditioned a high level of resistance against a mixture of powdery mildew isolates, which was virulent on powdery mildew resistance genes, including $P m 7, P m 8$, and $P m 17$ from rye. Together, these findings indicate that chromosome $2 \mathrm{R}$ of "German White" rye possesses a gene(s) for resistance to powdery mildew, which may differ from the previously identified $\mathrm{Pm} 7$ located on chromosome $2 \mathrm{RL}$ (Mclntosh et al. 2003). So far, the high levels of powdery mildew resistance provided by rye chromosome $2 \mathrm{R}$ have not been used effectively in wheat-breeding programs. Compared with "Xiaoyan 6", the newly developed 2R (2D) chromosome substitution lines were free of powdery mildew symptoms in the field, were highly resistant to powdery mildew isolates prevalent in northern China, had a high seed set, and were cytologically stable, making them useful in wheat improvement.

Using the monosomic method, Sears (1968) developed 2R (2B) and 2R(2D) "Chinese Spring" wheat-"Imperial" rye chromosome substitution lines. By substituting chromosome $2 R$ of rye into commercial wheat, May and Appels (1978) produced a double monosomic substitution line $2 \mathrm{R}(2 \mathrm{~B})$. Chapman and Miller (1978) developed 2R(2A), 2R(2B), and 2R(2D) "Holdfast" wheat-"King II" rye chromosome substitution lines. Merker and Rogalska (1984) reported a double disomic $1 \mathrm{R}(1 \mathrm{~B}), 2 \mathrm{R}(2 \mathrm{~B})$ wheat-rye chromosome substitution line that was free of powdery mildew symptoms in the field at the time, but this line was tall, susceptible to lodging, and low yielding (Merker and Forsström 2000). Friebe and Larter (1988) produced a disomic 2R(2D) "Thatcher" wheat-"Prolific" rye chromosome substitution line. Nevertheless, few wheat-rye chromosome substitution lines involving rye chromosomes $2 \mathrm{R}$ have been used extensively in wheat breeding because of agronomic disadvantages of the wheat genetic background, such as "Chinese Spring". The usefulness of wheat-alien hybrids depends, to some extent, on their wheat genetic backgrounds. In the present study, we considered not only the transfer of desirable genes of rye conferred by chromosome $2 \mathrm{R}$, but also placing them in a valuable background of common wheat "Xiaoyan 6" (An et al. 2000). The $2 R(2 D)$ wheat-rye chromosome substitution lines in the present study have a favorable wheat genetic background, which makes the new $2 \mathrm{R}(2 \mathrm{D})$ chromosome substitution lines more useful than the others.

Friebe and Larter (1988) suggested that rye chromosome $2 R$ was homoeologous to group 2 chromosomes of wheat and only the replacement of genetically homoeologous chromosomes was effective in producing fertile vigorous plants. The $2 \mathrm{R}(2 \mathrm{D})$ chromosome substitution lines described in the present study exhibited desirable agronomic characteristics, with vigorous vegetative growth and plump seeds with a high percentage of seed set (Table1; Figure 2A).

The present study demonstrates the effectiveness of developing an alien substitution line using the nullisomic back-crossing procedure ( $\mathrm{Li}$ et al. 1982). The wheat-rye $2 \mathrm{R}(2 \mathrm{D})$ chromosome substitution lines were developed from $\mathrm{BC}_{2} \mathrm{~F}_{2}$ plants that originated from the cross between nullisomics $2 \mathrm{D}$ wheat and rye. Compared with the monosomic method that needs at least eight to nine generations to produce an alien chromosome substitution line, the nullisomic back-crossing procedure shortened the duration to only four to five generations. In addition, the method used in the present study necessitates fewer cytological examinations (Zhang et al. 1989). The present study 
provides an additional example of producing a chromosome substitution line using the nullisomic back-crossing method. However, the prerequisite of developing an alien chromosome substitution line using the nullisomic back-crossing procedure is the availability of nullisomic wheats that are fertile and have a high seed set. We developed fertile nullisomics 2D derived from monosomic 2D of "Xiaoyan 6", which grows vigorously with an average seed set of over $60 \%$. By using this nullisomic line, chromosome $2 \mathrm{R}$ of rye was transferred into "Xiaoyan 6" wheat resulting in $2 \mathrm{R}(2 \mathrm{D})$ chromosome substitution lines. Moreover, we had developed cytologically stable and fertile IA, IB, ID, 2A, 2B, 3B, 4A, 5A, 5B, 5D, 6A, 6D, and 7D nullisomics of "Xiaoyan 6" (An et al., 2002, unpublished data). These nullisomic lines are useful for producing wheat-rye chromosome substitution lines by means of nullisomic backcrossing procedure.

GISH using total genomic DNA as a probe facilitates the identification of alien chromosomes and chromosome segments in wheat backgrounds. PCR using chromosome-specific primers proved to be a powerful tool for the identification of alien chromatin that had been introgressed into common wheat (Lee et al. 1993). In the present study, chromosome $2 \mathrm{R}$ was identified by $\mathrm{PCR}$ with primers specific for $2 \mathrm{R}$ (Figure 3 ). Combining results obtained by cytological, GISH, and PCR analyses, lines WR02145 were determined to be a wheat-rye chromosome substitution line involving the rye chromosome $2 \mathrm{R}$ (Figure $2 \mathrm{C}$ ).

\section{Materials and Methods}

\section{Plant materials}

Four wheat-rye WR02-145 lines, designated WR02-145-1, WR02-145-2, WR02-145-3, and WR02-145-4, and the winter rye cultivar "German White" (Sun 2002) were used in the present study. Winter wheat cultivar Triticum aestivum L. "Xiaoyan 6" was developed from a cross of St 2422/464/T. aestivum "Xiaoyan 96" in Shanxi Province, PR China, in 1981 (Zhuang 2003). Self-pollinated, fertile, and cytologicaly stable nullisomic $2 \mathrm{D}(2 \mathrm{n}=40, \mathrm{AABBDD}-2(2 \mathrm{D}))$ was derived from the selfed progeny of monosomic $2 \mathrm{D}$ of the wheat cultivar $T$. aestivum "Xiaoyan 6". The monosomic 2D line of "Xiaoyan 6" was produced by repeated back-crossing of the monosomic 2D line of wheat cultivar T. aestivum "Chinese Spring" to "Xiaoyan 6" as the male parent seven times. Wheat cultivar $T$. aestivum "Mingxian 169" was used as the susceptible control in powdery mildew tests. The "Chinese Spring" wheat-"Imperial" rye $2 \mathrm{R}(2 \mathrm{D})$ chromosome substitution line, kindly provided by Dr S. Reader (John Innes Centre, Norwich, UK), was used as a control in the detection of $2 \mathrm{R}$ rye chromatin by PCR. Lovrin 10 and Lovrin 13, which are T1BL-1RS translocation lines (Rabinovich 1998), were also used as controls in the PCR analysis.

Production of wheat-rye chromosome substitution lines by the nullisomic back-crossing procedure

The nullisomic back-crossing procedure (Li et al. 1982) was used to produce the wheat-rye chromosome substitution lines in the present study. "Xiaoyan 6" nullisomic 2D was crossed with "German White" rye and, 16-18 d following pollination, inflorescences were stored at $4{ }^{\circ} \mathrm{C}$ in a refrigerator for $48-72$ h (Sharma 1995). Hybrid embryos were dissected from spikes and placed on MS medium (Murashige and Skoog 1962). Following chromosome doubling with a solution containing $0.05 \%$ colchicine, $1.5 \%$ dimethylsulfoxide, and $5 \%$ MS medium (An et al. 2003), amphidiploid plants were obtained and back-crossed as the female parent to the nullisomic $2 \mathrm{D}$ line. Plants of $\mathrm{BC}_{1} \mathrm{~F}_{1}$ were screened for resistance to powdery mildew and resistant plants were again back-crossed as the female parent to the nullisomic $2 \mathrm{D}$ line. The $\mathrm{BC}_{2} \mathrm{~F}_{1}$ plants were tested for resistance to powdery mildew and karyotyped by cytological examination. Plants with chromosome numbers $2 n=41$ were allowed to self-pollinate. Vigorous and fertile selfed progenies $\left(\mathrm{BC}_{2} \mathrm{~F}_{2}\right.$ plants) with somatic cell chromosome number $2 \mathrm{n}=42$ were selected for further characterization. During development, each individual plant was selected for high seed set, wheatlike plant type, and resistance to powdery mildew. The subsequent generations were self-pollinated and planted in the field.

\section{Evaluation of reaction to powdery mildew}

\section{Greenhouse tests}

Powdery mildew inoculation and disease assessments were conducted in a greenhouse, as described by Sheng (1988). At the two- to three-leaf stage, plants of wheat-rye derivatives, "Xiaoyan 6", nullisomic 2D, "German White" rye, and "Mingxian 169 " were artificially inoculated with a mixture of the powdery mildew isolates prevailent in northern China. The isolate mixture was virulent on powdery mildew resistance genes $P m 1$, Pm3a, Pm3b, Pm3c, Pm3d, Pm3e, Pm 3f, Pm5, Pm6, Pm 7, $P m 8, P m 17$, and $P m$ 19, and avirulent on genes Pm2, Pm4a, $P m 4 b, P m 12, P m 13, P m 16, P m 20$, and $P m 21$, as determined by differential cultivars (Duan 1998). Infection types were scored $15 \mathrm{~d}$ after inoculation, when the susceptible wheat check "Mingxian 169" was heavily infected, using a scale of 0 4 , where $0=$ no visible symptoms, 0 ;=necrotic flecks, and $1-$ 4=highly resistant, resistant, susceptible, and highly susceptible reactions, respectively (Sheng 1988).

\section{Field tests}

The wheat-rye derivatives were planted in six-row plots, each of which were $1.5 \mathrm{~m}$ long and spaced at $25 \mathrm{~cm}$, in early October. The plots were arranged in a randomized block design with 
three replications. "German White" rye was grown in a single row and the susceptible check cultivar "Mingxian 169" was grown in double rows beside the plots as a mildew spreader. In mid-November, and then in late March, the spreader rows were inoculated twice with a mixture of powdery mildew isolates, as described previously. Disease severity was assessed on a scale (0-9) as described by Sheng and Duan (1991). Infection types (scale 0-4) were scored on the upper four leaves on 5, 13, and 20 May. The field test was repeated in the following year's growing season using the same procedure.

\section{PCR}

In the present study, PCR amplification was used to detect the alien chromatin in wheat-rye derivatives. Total genomic DNA was isolated from seedling using the phenol/chloroform method (Sharp et al. 1988). The primers (R1: 5'-CCCAGCAACAACAACCGTCGATTC-3'; R2:5'-AATCGACGGTTGTTGTTGCTGGG-3'), which were derived from the partial cDNA clone pSC 503 of a rye gamma secaline gene (Kreis et al. 1985), were used. The 473-bp PCR product was detected in lines carrying either $2 \mathrm{R}$ or $2 R S$ of rye (Lee et al. 1993). DNA amplification was conducted in a $25 \mu \mathrm{L}$ reaction volume containing $1 \times$ Taq PCR buffer, 1.0 unit of Taq DNA polymerase, $0.25 \mu \mathrm{mol} / \mathrm{L}$ of each primer, 200 $\mu \mathrm{mol} / \mathrm{L}$ of each deoxyribonucleotide, and $280 \mathrm{ng}$ sample DNA. The PCR was performed in a PTC-200 Peltier Thermal Cycler (MJ Research, Ramsey, MN, USA) using a program of $95^{\circ} \mathrm{C}$ for $5 \mathrm{~min}, 35$ cycles at $94^{\circ} \mathrm{C}$ for $1 \mathrm{~min}, 56^{\circ} \mathrm{C}$ for $2 \mathrm{~min}$, and $72^{\circ} \mathrm{C}$ for $1 \mathrm{~min}$, with an extension at $72^{\circ} \mathrm{C}$ for $10 \mathrm{~min}$. The $\mathrm{PCR}$ products were separated on $1.5 \%$ agarose gels in $1 \times$ TBE buffer ( 89 $\mathrm{mmol} / \mathrm{L}$ Tris-borate, $2 \mathrm{mmol} / \mathrm{L}$ EDTA, $\mathrm{pH}$ 8.3) for $90 \mathrm{~min}$ at $110 \mathrm{~V}$.

\section{Cytological analyses}

Root tips were removed from germinated seeds and pretreated in ice water for $24 \mathrm{~h}$ prior to fixation (ethyl alcohol : acetic acid=3:1, v/v) for $24 \mathrm{~h}$. The fixed root tips were hydrolyzed in $1 \mathrm{~mol} / \mathrm{L} \mathrm{HCl}$ for $3-4 \mathrm{~min}$ at $65^{\circ} \mathrm{C}$, prestained in $4 \%$ ferrovanadium solution for $25 \mathrm{~min}$, and then stained in $0.5 \%$ hematoxylin for 1 h. Mitotic chromosomes were prepared by squashing root tips in $45 \%$ acetic acid. Chromosomes were viewed with an Olympus BH-2 microscope (Olympus Optical, Tokyo, Japan). Anthers containing PMCs at the metaphase I stage were fixed in Carnoy solution (absolute alcohol: acetic acid : chloroform = $6: 3: 1$ ) for 2 days and stored in $70 \%$ ethanol at $4{ }^{\circ} \mathrm{C}$ until use. The anthers were briefly stained with a drop of $2 \%(\mathrm{v} / \mathrm{v})$ acetocarmine and the PMCs were squashed. Meiotic preparation slides were examined to analyze chromosome pairing configurations.

\section{GISH analysis}

To detect rye chromatin in the WR02-145 lines, GISH analysis with total genomic DNA from "German White" rye was performed on mitotic metaphase chromosome preparations. Root tips were fixed and then squashed onto ethanol-washed microscope slides in $45 \%$ acetic acid and cover slips were removed after being frozen in liquid nitrogen. Slides were airdried overnight at room temperature and then stored at $-20^{\circ} \mathrm{C}$ until GISH analysis.

Total genomic DNA of "German White" rye was sonicated into 500-800-bp fragments and labeled with DIG-Nick Translation Mix (Roche, Mannheim, Germany). The blocking DNA was prepared by shearing the total genomic DNA extracted from "Chinese Spring" wheat (ABD genomes) and was mixed with the DNA probe in a ratio of $30: 1$. The GISH was performed as described by Reader et al. (1994). The wheat chromosomes were counterstained red by PI. The bright-greenish fluorescein isothiocyanate (FITC) hybridization signals were then examined using a Nikon Eclipse E600 fluorescence microscope (Nikon, Tokyo, Japan). Photographs were taken with a Spot CCD camera (Diagnostic Instruments, Sterling Heights, MI, USA).

\section{Acknowledgements}

The authors are grateful to Dr Yilin Zhou of the Plant Protection Institute, the Chinese Academy of Agricultural Sciences, for conducting the powdery mildew tests.

\section{References}

An DG, Zhong GC, Mu SM, Li JM, Wang ZG, Wang YM (2000). The development of a set of wheat-rye substitution lines with background of wheat variety Xiaoyan No.6. Acta Agr Biotechnol 18 (Suppl.), 67-70 (in Chinese with an English abstract).

An DG, Zhong GC, Li JM, Wang ZG, Wang YM, Ji J (2003). Study on chromosome doubling methods of immature embryo plants of wheat distant hybridization. Acta Agron Sin 29, 955-957. (in Chinese with an English abstract).

Asiedu RJ, Fisher M, Driscoll CJ (1990). Resistance to Heterodera avenae in the rye genome of triticale. Theor Appl Genet 79, 331-336.

Brunell MS, Lukaszewski AJ, Whitkus R (1999). Development of arm-specific RAPD marker for rye chromosome $2 \mathrm{R}$ in wheat. Crop Sci 39, 1702-1706.

Chapman V, Miller TE (1978). Alien chromosome addition and substitution lines. In: Plant Breeding Institute, ed. Annual Report of the Plant Breeding Institite. Cambridge, England. pp. $124-125$.

Duan XY, Sheng BQ, Zhou YL, Xiang QJ (1998). Monitoring of the virulence population of Erysiphe graminis DC. f. sp. tritici E. Marchal. Acta Phtophyl Sin 25, 31-36 (in Chinese with an English abstract).

Friebe B, Larter EN (1988). Identification of a complete set of 
isogenic wheat/rye D-genome substitution lines by means of Giemsa C-banding. Theor App/ Genet 76, 473-479.

Friebe B, Hattchet JH, Sears RG, Gill BS (1990). Transfer of hessian fly resistance from "Chaupon" rye to hexaploid wheat via a 2BS/ 2RL wheat-rye chromosome translocation. Theor Appl Genet 79, 385-389.

Friebe B, Heun M, Tuleen N, Zeller FJ, Gill BS (1994). Cytogenetically monitored transfer of powdery mildew resistance from rye into wheat. Crop Sci 34, 621-625.

Heun M, Friebe B (1990). Introgression of powdery mildew resistance from rye into wheat. Phytopathology 80, 242-245.

Hu H, Tao YZ, Wang G (1988). Creating new types of wheat via anther culture. In: Miller TE, Koebner RMD, eds. Proceedings of the 7th International Wheat Genetics Symposium. Cambridge, England. pp. 1101-1104.

Kota RS, Dvoák J (1985). A rapid technique for substituting alien chromosomes into Triticum aestivum and determining their homoeology. Can J Genet Cytol 27, 549-558.

Kreis M, Forde BG, Rahman S, Miflin BJ, Shewry PH (1985). Molecular evolution of the seed storage proteins of barely, rye and wheat. J Mol Biol 183, 499-502.

Le HT, Armstrong KC, Miki B (1989). Detection of rye DNA in wheatrye hybrids and wheat translocation stocks using total genomic DNA as a probe. Plant Mol Biol Rep 7, 150-158.

Lee JH, Graybosch RA, Lee DJ (1993). Detection of rye chromosome $2 \mathrm{R}$ using the polymerase chain reaction and sequencespecific DNA primers. Genome 37, 19-22.

Li HJ, Zhu ZQ, Zhang YM, Guo BH, Wen YX, Jia X (1998). Molecular cytogenetic identification of Triticum aestivum-Secale cereale substitution and addition lines. Acta Bot $\operatorname{Sin}$ 40, 37-41 (in Chinese with an English abstract).

Li WL, Li ZS, Mu SM (1990). A cytological study of chromosomal structure change in a common wheat variety "Xiaoyan 6". Acta Genet Sin 17, 430-437. (in Chinese with an English abstract).

Li ZS, Mu SM, Chen SY (1982). Study on blue-grained monosomic wheat. Acta Genet $\operatorname{Sin}$ 9, 431-439 (in Chinese with an English abstract).

Lind $\mathbf{V}$ (1982). Analysis of the resistance of wheat-rye addition lines to powdery mildew of wheat (Erysiphe graminis f. sp. tritici). Tagungsber Akad Landwirt Wiss DDR 198, 509-520.

May CE, Appels R (1978). Rye chromosome 2R substitution and translocation lines in hexaploid wheat. Cereal Res Commun $\mathbf{6}$, 231-234.

McIntosh RA, Friebe B, Jiang JD, Gill BS (1995). Cytogenetic studies in wheat XVI. Chromosome location of a new gene for resistance to leaf rust in a Japanese wheat-rye translocation line. Euphytica 82, 141-147.

McIntosh RA, Yamazaki Y, Devos KM, Dubcovsky J, Rogers WJ, Appels R (2003). Catalogue of gene symbols for wheat. In: Pogna NE, Romanò M, Pogna EA, Galterio G, eds. Proceedings of the 10th International Wheat Genetics Symposium. Paestum, Italy. pp. 1-6.
Merker A, Forsström PO (2000). Isolation of mildew resistant wheatrye translocation lines from a double substitution line. Euphytica 115, 167-172.

Merker A, Rogalska S (1984). The breeding behavior of a double disomic wheat-rye substitution line. Cereal Res Commun 12, 13-17.

Miller TE (1984). The homoeologous relationships between the chromosome of rye and wheat. Current status. Can J Genet Cytol 26, 578-589.

Mukai Y, Nakahara Y (1993). Simultaneous discrimination of the three genomes in hexaploid wheat by multicolor fluorescence in situ hybridization using total genomic and highly repeated DNA probes. Genome 36, 489-494.

Mukai Y, Friebe B, Gill BS (1992). Comparison of C-banding patterns and in-situ hybridization sites using highly repetitive and total genomic rye DNA probes of "Imperial" rye chromosomes added to "Chinese Spring" wheat. JPN J Genet 67, 71-83.

Murashige T, Skoog F (1962). A revised medium for rapid growth and bioassays with tobacco tissue culture. Physiol Plant 15, 473-497.

Nkongolo KK, Armstrong KC, Comeau A, Pierre CAS (1992). Identification of rye chromosomes involved in tolerance to barley yellow dwarf virus disease in wheat $\times$ triticale hybrids. Plant Breeding 109, 123-129.

Rabinovich SV (1998). Importance of wheat-rye translocation for breeding modern cultivars of Triticum aestivum L. Euphytica 100, 323-340.

Reader SM, Abbo S, Purdie KA, King IP, Miller TE (1994). Direct labeling of plant chromosomes by rapid in situ hybridization. Trend Genet 10, 265-266.

Rogowsky PM, Sorrels ME, Shepherd KW, Langride P (1993). Characterization of wheat-rye recombinants with RFLP and PCR probes. Theor Appl Genet 85, 1023-1028.

Schlegel R, Melz G, Korzun V (1998). Genes, markers and linkage data of rye (Secale cereale L.): 5th updated inventory. Euphytica 101, 32-67.

Schwarzacher T, Leitch AR, Bennett MD, Heslop-Harrison JS (1989). In situ hybridization of parental genomes in a wide hybrid. Ann Bot 64, 315-324.

Sears ER (1968). Relationships of chromosomes 2A, 2B and 2D with their rye homoeologous. In: Finlay KW, Shephard KW, eds. Proceedings of the 3rd International Wheat Genetics Symposium. Canberra, Australia. pp. 53-61.

Sebesta EE, Wood EA, Porter DR, Webster JA, Smith EL (1994). Registration of Amigo wheat germplasm resistance to greenbug. Crop Sci 34, 293.

Sharma HC (1995). How wide can a wide cross be? Euphytica 82, 43-64.

Sharp PJ, Kreis M, Shewry PR, Gale MD (1988). Location of $\beta$ amylase sequences in wheat and its relatives. Theor Appl Genet 75, 286-290.

Sheng BQ (1988). Powdery mildew scored by infection reaction 
pattern at the seedling stage. Plant Protect 14, 49-50 (in Chinese with an English abstract).

Sheng BQ, Duan XY (1991). Improvement on a scale (0-9) assessment of adult plant resistance to powdery mildew. Beijing Agric Sci 1, 38-39 (in Chinese with an English abstract).

Stewart DM, Gilmore EC, Ausemus ER (1968). Resistance to Puccinia graminis derived from Secale cereale incorporated into Triticum aestivum. Phytopathology 58, 508-511.

Sun YS (2002). Triticale Genetic Breeding and Utilization in China. Zhejiang Scientific and Technologic Press, Hangzhou (in Chinese).

Wei YM, Zhang GQ, Ouyang SH, Xi ML, Hu XZ (2000). Aspect and problem on quality improvement of wheat variety in Guanzhong Plain of Shanxi Province. J Triticeae Crops 20, 3-9 (in Chinese with an English abstract).

Wilson AS (1875). On the fertilization of the cereals. Trans Proc Bot Soc $12,237-242$.
Xu Q, Li ZS, Chen SY (1992). Study on developing Triticum-Aegilops substitution line by nullisomic backcrossing procedure. Acta Bot Boreal-Occident $\operatorname{Sin}$ 1, 9-16 (in Chinese with an English abstract).

Zeller FJ, Hsam SLK (1983).Broadening the genetic variability of cultivated wheat by utilizing rye chromatin. In: Sakamoto S, ed. Proceedings of the 6th International Wheat Genetics Symposium. Kyoto, Japan.pp. 161-173.

Zhang XY, Li ZS, Chen SY (1989). Studies on the nullisomic backcrossing procedure for producing alien substitution lines. Acta Genet Sin 16, 420-429 (in Chinese with an English abstract).

Zhang XY, Chen SY, Li ZS (1990). Producing and utilization of alien substitution lines of common wheat. Hereditas, 12, 40-44 (in Chinese with an English abstract).

Zhuang QS (2003). Chinese Wheat Improvement and Pedigree Analysis. Chinese Agricultural Press, Beijing.

Zhuang QS, Li ZS (1993). Present status of wheat breeding and related genetic study in China. Wheat Inf Serv 76, 1-15.

(Managing editor: Li-Hui Zhao) 